\title{
Water tracks in the lower Lena River basin
}

\author{
Anna Tarbeeva ${ }^{1 *}$, Lyudmila Lebedeva ${ }^{2}$, Vladimir Efremov ${ }^{2}$, Vladimir Shamov ${ }^{3,2}$, and Olga \\ Makarieva $^{2,4}$ \\ ${ }^{1}$ Lomonosov Moscow State University, 119991, Leninskiye Gory, 1, Moscow, Russia \\ ${ }^{2}$ Melnikov Permafrost Institute SB RAS, 677010, Merzlotnaya St., 36, Yakutsk, Russia \\ ${ }^{3}$ Pacific Geographical Institute FEB RAS, 690041, 7 Radio str., Vladivostok, Russia \\ ${ }^{4}$ St. Petersburg State University, 199034, Universitetskaya Emb., 7-9, St. Petersburg, Russia
}

\begin{abstract}
In the permafrost regions, where water filtration zone is limited by the shallow active layer, the surface flow forms a network of hollows, called «water tracks», oriented along the slope gradient. Water tracks are clearly distinguished on satellite images, but poorly defined in the field. The pattern of the water tracks network depends on geomorphological position, permafrost and geological conditions and dominant cryogenic processes. Surface flow could occur in the water tracks during the snowmelt and heavy rains, when the soil is entirely frozen or fully saturated by water. In dry periods, the water tracks form retention zones due to low filtration rates and significant capacity of thawed soil beneath the troughs. Our study of water tracks in the north-western Yakutia showed the changes of their morphology from upstream towards downstream. The water levels in the water tracks have a pronounced diurnal course in reverse phase to the water temperature variation. They are related to diurnal ground thawing dynamics. Hydrology of water tracks depends on the peat thickness, active layer properties and lithology. Water tracks formed by rubble rocks respond to a storm event with rapidly increasing water level. The deeper thawing layer, the smoother water levels rise and decrease.
\end{abstract}

\section{Introduction}

In the permafrost soils water filtration zone is limited by the depth of seasonal thawing. The runoff on the hillslopes is concentrated along a network of poorly defined depressions with high soil moisture, called "dells" [1-4] or "water tracks" [5-10]. They form distinctive drainage pattern, which is observed in permafrost environment only. In aerial and satellite images this drainage pattern looks like dense network of sub-parallel stripes oriented strictly down the slope gradient. The length of the stripes could reach several kilometres. The width varies from 1-2 to the first tens of meters, and the depth usually does not exceed $0.5 \mathrm{~m}$.

There are various hypothesis about the mechanisms of formation of these hollows. Mitt [1] found erosion grooves filled with silt and sand with gravel in the bottoms of dells and associated the formation of dells with erosion, although he noted the significant role of

\footnotetext{
*Corresponding author: amtarbeeva@yandex.ru
} 
cryogenic processes in preparing the material for removal. Katasonova [2] related this phenomenon to thermokarst, since ice-rich horizon in the bottoms of the dells was absent while it was found on the adjacent parts of the slope. Voskresensky [3] studied structure of the slope deposits and associated the formation of dells with defluction and gelifluction. Paquette [10] speculates that the water track formation was initiated by a combination of sorting, differential frost heaving, and eluviations. Hall [4] drew attention to the role of large mammals (muskox, mammoth and rhinoceros) in the activation of thermoerosion processes along the ice wedges, which could lead to the formation of dells. McNamara [8] reported that water tracks do not possess the fractal similarity of the dendritic pattern of channel network. He suggested that they originated from rudimentary erosion network, the development of which is limited by the frozen ground.

The hydrological properties of the water tracks are well studied in Alaska. A typical storm hydrograph in the basins with a developed water tracks network shows fast initial response to storm event, an extended recession and long lag between the hyetograph and hydrograph centroids [7]. The peat-covered water tracks act as large storage reservoirs, but when saturated they generate fast runoff reaction. During the snowmelt, most of the water flow is formed by "new" water, while during the rain storms the proportion of "old" and "new" water depends on the antecedent soil saturation («old water» is the water that existed in the basin before the storm or snowmelt) [6].

In Russia, hydrological role of the water tracks is poorly studied. Different hypothesis about their origin suggest their significant diversity including presumably varying hydrological functioning.

\section{Methods}

In 2018-2019 we examined the physical and hydrological properties of the water tracks in the upper Crest-Yuryakh River basin, tributary of the Bykovskaya channel of the Lena River Delta (north-western Yakutia, Russia) to evaluate their formation process and hydrological functioning. The territory is an arctic tussock tundra with low elevated remnant hills (150-200 $\mathrm{m}$ a.s.1.), branches of the Kharaulakh ridge. The bedrock, exposed at the tops of the hills, is represented by Paleozoic mudstones and carbonates. Gentle slopes are covered by ice-rich silts and sandy loams. The slopes are dissected by water tracks entering the first-order channels. The territory is covered by continuous permafrost. The mean annual air temperature is $-12.7^{\circ} \mathrm{C}$, and the active layer thickness does not exceed $0.5 \mathrm{~m}$.

Water temperature and level were measured at the upper («1»), middle («2») and lower $(« 2 »)$ sections of water track by automated data loggers (Fig. 1). The recorders were installed in the pits excavated in the bottom of the water track and covered with the original soil. Leveling of topography combined with thaw-depth measurement using a steel probe were carried out along the three profiles on the gauging stations. The sediments structure of the active layer was described in the pits.

Water level and temperature in water track were observed in different hydrometeorological conditions. In August 2018 there was no precipitation during the two weeks of observation. In August 2019, precipitation fell in the middle of the observation period. In 2019, measurements were carried out in three sections: in the upper, middle, and lower reaches of the same water track. Observations in 2018 were carried out only in the middle section.

In 2018, when surface flow was absent, water filtration rates were measured in the water track and in the intertrack (area between two water tracks) by introducing a $\mathrm{NaCl}$ solution $(100 \mathrm{mg} / \mathrm{l})$ to the pits and measuring the electrical conductivity in the pits located downslopes. In 2019 soil temperature was measured at different depths of the active layer in the intertrack using data loggers. All measurements were made with 30 minute intervals. 
Precipitation data was taken from the «Stolb» («Khabarovo») weather station, located 1.5 $\mathrm{km}$ from the studied water track.

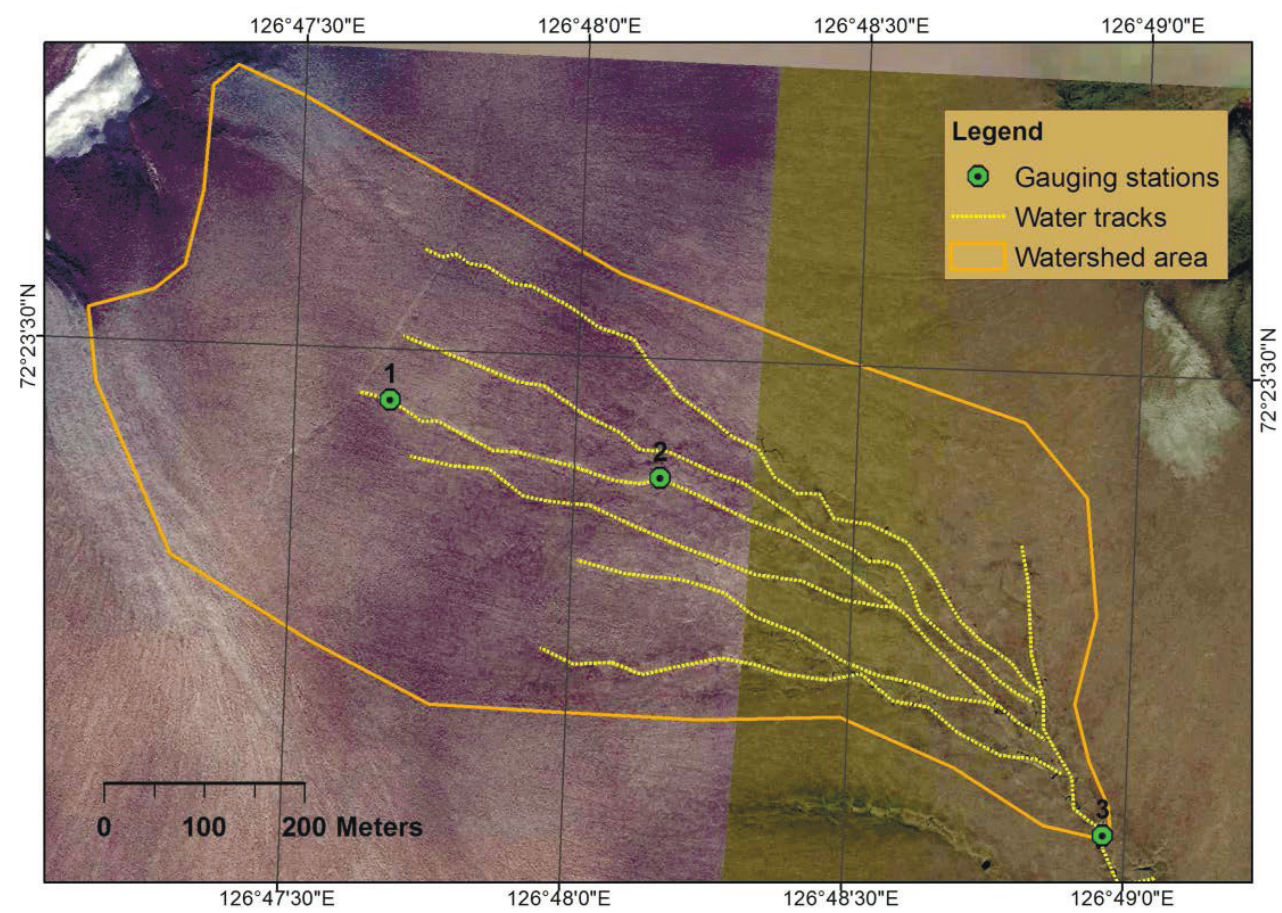

Fig. 1. Location of the gauging stations on the water track in the headwater of Crest-Yuryakh River: 1 - Upper station $\left(126^{\circ} 47^{\prime} 40,377^{\prime \prime E} \quad 7^{\circ} 23^{\prime} 28,303^{\prime \prime N}\right) ; 2$ - Middle station $\left(126^{\circ} 48^{\prime} 9,47^{\prime \prime} \mathrm{E}\right.$ $\left.72^{\circ} 23^{\prime} 26,041^{\prime \prime N}\right) ; 3$ - Lower station $\left(126^{\circ} 48^{\prime} 57,882^{\prime \prime} \mathrm{E} 72^{\circ} 23^{\prime} 15,097 " \mathrm{~N}\right)$. (The image from SakhaGIS (https://sakhagis.ru/) was used as a background).

\section{Results and discussions}

\subsection{Morphology}

The studied water track is located on a gentle (4-6 degree gradient) concave slope in the upper Crest-Yuryakh River basin. Water track initiates near the top of the hill and ends in the valley bottom in a headwater of Crest-Yuryakh Creek. The upper part of the hill is dissected by series of moss-covered depressions-strips, composed mainly of porous coarse rubble $5-10 \mathrm{~cm}$ in size, where fine material was washed out. Depressions are separated by hummocks, which are poorly vegetated and composed of sandy loam with some stones. Depressions have a width of 0.5-1 $\mathrm{m}$ and are spaced 2-3 $\mathrm{m}$ apart, often intertwined. Presumably, they are initiated by a combination of sorting, differential frost heaving, and eluviations, and resemble that described in $[10,11]$. The thawing depth under the hummocks exceeds $45 \mathrm{~cm}$, that is greater than under the depressions $(25 \mathrm{~cm})$. Measurements of water filtration rates in the depressions showed a value of $14 \mathrm{~m}$ per day.

Down the slope, near the Upper gauge station («1» at the Fig. 1), flow is concentrated in water track up to $0.5 \mathrm{~m}$ deep, 1-3 m wide, covered by moss and peat $5-10 \mathrm{~cm}$ thick and underlain mainly of loams with rare coarse material. The thawing depth under the hollow doesn't differ from that of its edge $(25-30 \mathrm{~cm})$. 
In middle part of the water track ( «2» at the Fig. 1) the width reaches 4-6 m, the thawing depth under the water track slightly exceeds the thawing depth of intertracks (39 and $27 \mathrm{~cm}$, respectively). The active layer consists of silt with peat interlayers without coarse material. The measured gravimetric ice content in the frozen sediments near the frost table often exceeds $100 \%$. At low water period, flow filtration rates in the bottom of water track are $3.5 \mathrm{~m}$ per day and do not differ from such in adjacent intertracks.

In the foothills («3» at the Fig. 1) several water tracks merge, their bottoms expand up to 20-30 m, become swampy, the thickness of peat and moss increases up to $15-20 \mathrm{~cm}$. Signs of thermokarst appear in the water track floor, namely angled flooded depressions. They are probably inherited from the ice wedge polygons. The thawing depth in the bottom of the water track increase significantly (up to $45-50 \mathrm{~cm}$ ) compared with the surrounding slopes $(25-30 \mathrm{~cm})$.

\subsection{Hydrology}

In the absence of precipitation (August 2018), the water level and temperature in the water track had a pronounced diurnal variation. The level course was out of phase with the water temperature (Fig. 2). This could be explained by the diurnal course of thawing of the icereach active layer, due to the fact that the daily maximum of air temperature reaches the thawing front in the soil layer after 8-12 hours (Fig. 3), which leads to the introduction of an additional portion of cold water. The second reason for reverse phase between water level and ground temperature in water tracks may be the daily course of condensation and evapotranspiration.

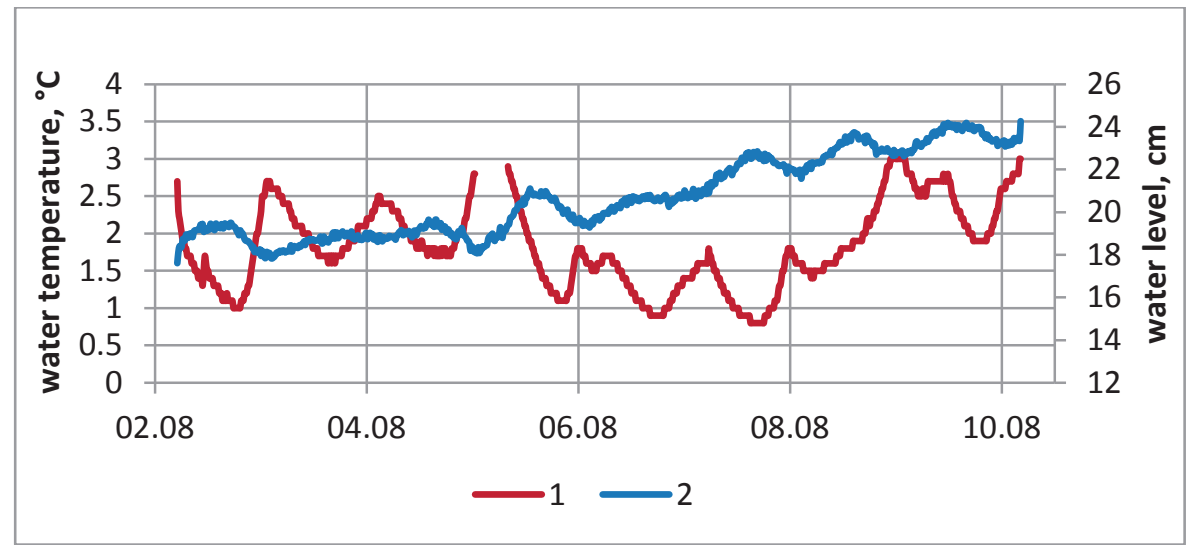

Fig. 2. Water temperature (1) and water level (2) in the middle section of the water track at low water period, August 2018.

In August 2019 the response to the precipitation was different in the upper, middle and lower sections of the water track (Fig. 4).

Above the upper section of the water track the runoff is formed in strips of stones. The reaction to the rain at the upper section was fast, as well as the recession. The reaction to the second rain was clearly expressed in the form of a second peak. In the middle part of the water track, where its floor is composed of peat and silt, two peaks of the water level were also observed. Water level rise and recession were smoother than in the upper section. In the lower section, where the thawing depth increases and thermokarst develops, one peak of levels was formed with a gentle rise and fall as a result of two rains. Rain led to a decrease in water temperature and disruption of its diurnal course in all three gauging stations (Fig. 5). 


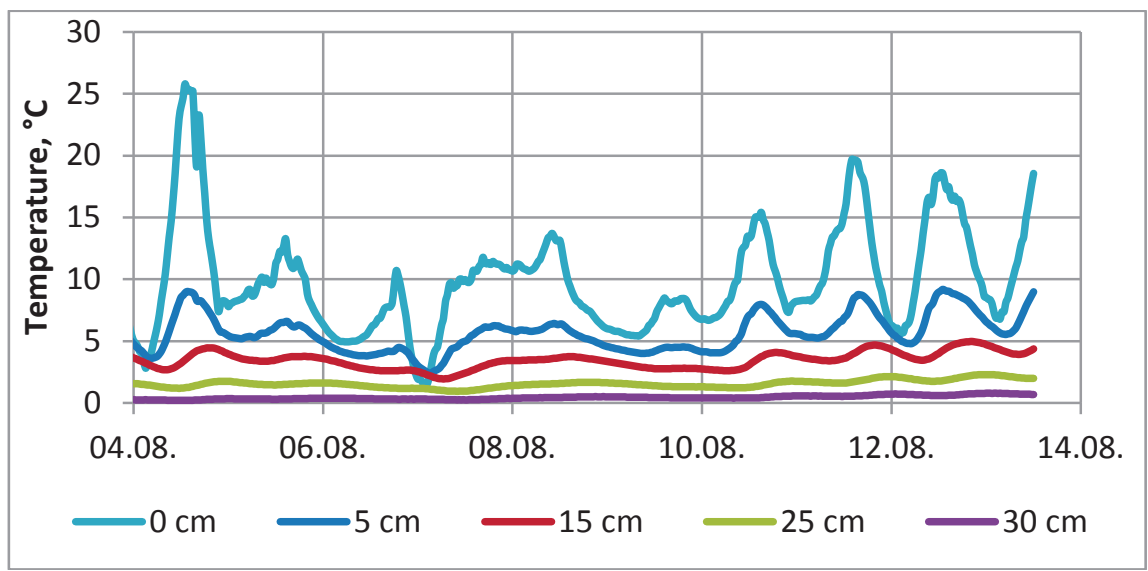

Fig. 3. Soil temperature dynamics at different depths of the active layer in the intertrack near the middle gauging station, August 2019.

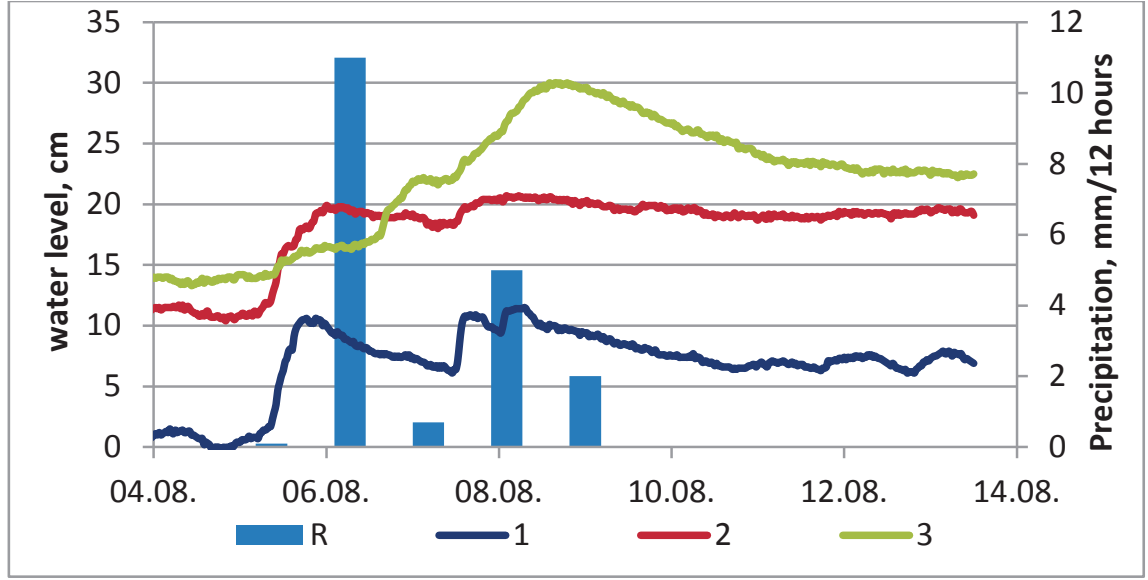

Fig. 4. Precipitation (R, [mm/12 hours]) and water level [cm] at different sections of the water track during the storm event (August 2019): 1 - upper section; 2 - middle section; 3 -lower section.

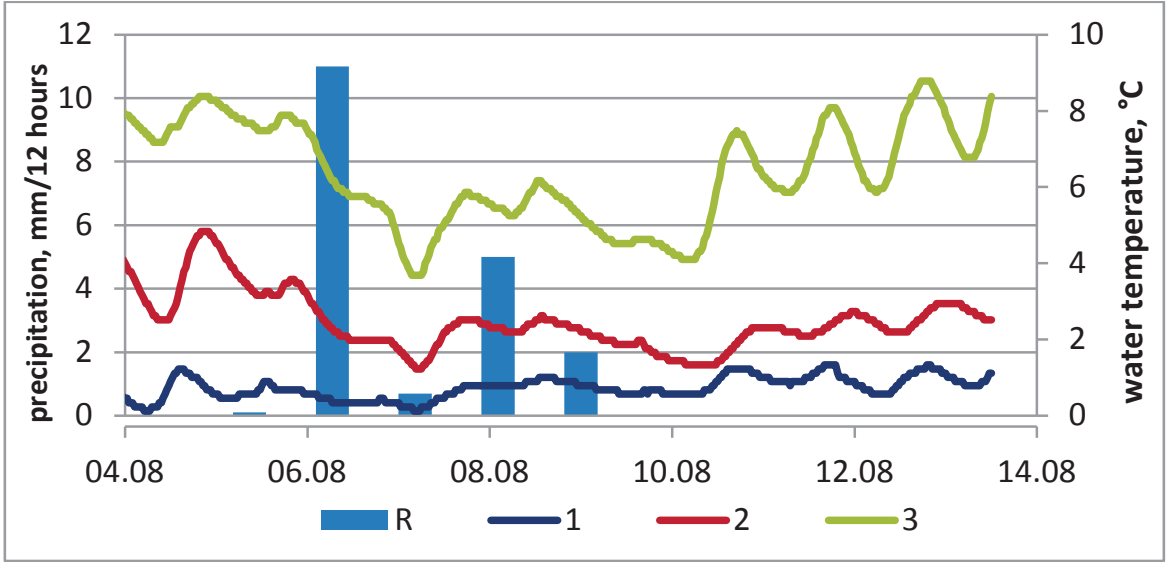

Fig. 5. Precipitation $(R)$ and water temperature at different sections of the water track during the storm event (August 2019): 1 - upper section; 2 - middle section; 3 - lower section. 


\section{Conclusions}

Despite the widespread occurrence in the permafrost environments, the morphology, stratigraphy and cryogenic structure of the water tracks are diverse. Morphometry, peat thickness, sediment composition, thaw depth and the cryogenic processes vary within one water track down the slope.

The diurnal fluctuation of the water levels and temperatures is determined by the diurnal dynamics of ground thawing and evaporation. Differences in the morphology, composition of sediments, the thawing depth and the slope gradients in the different types of water tracks, as well as the antecedent saturation, lead to different hydrological response to summer precipitation.

The reported study was funded by RFBR, projects number 20-05-00840, 20-35-70027, 18-05-60036, and contributes to the State Task no. AAAA-A16-116032810084-0, Faculty of Geography MSU.

\section{References}

1. Mitt K.L. On the nature of dells in the Daldyn diamond region. Issues of Geography. 46. 28-34. (Moscow. Geografgiz Publ. 1959). (in Russian).

2. Katasonova E.G. Conditions and features of the development of frozen strata in Siberia and the North-East. 91-100. (Moscow. AN USSR Publ. 1963). (in Russian).

3. Voskresenskij S.S. Dynamic geomorphology. Formation of slopes. 230. (Moscow: MSU Publ. 1971). (in Russian).

4. Hall K. Polar Geography. 21. 1. 1-9. (1997).

5. Kane D.L., Hinzman L.D., Benson C.S., and Liston G.E. Water Resour. Res. 27. 6. 1099-1109. (1991).

6. McNamara J.P., Kane D.L., and Hinzman L.D. Water Resour. Res. 33. 7. 1707-1719. (1997).

7. McNamara J.P., Kane D.L., and Hinzman L.D. J. of Hydrology. 206. 39-57. (1998).

8. McNamara J. P., Kane D.L., Hinzman L.D. Geomorphology. 29. 339-353. (1999).

9. Woo M.-K. Permafrost Hydrology. 572. (Springer-Verlag Berlin Heidelberg, 2012).

10. Paquette M., Fortier D., and Vincent W. F. Arctic Science. 3. 334-353. (2017)

11. Hodgson R., Young K.L. Earth Surf. Process. Landf. 26. 319-328. (2001). 